\title{
A comparison of unrefined wheat and rice diets in the management of duodenal ulcer
}

\author{
S. L. MALHOTRA \\ F.R.C.P.(Lond.), D.C.H.(Eng.), D.P.H.(Lond.), D.I.H.(Eng.) \\ Chief Medical Officer and Head of Medical Department, South Eastern Railway Hospital, \\ Calcutta-43, India
}

\begin{abstract}
Summary
Twenty-one chronic duodenal ulcer patients in a riceeating area were put on to an unrefined wheat diet and twenty-one continued on their previous rice diet. After 5 years only $14 \%$ of the first group had had relapses compared with $81 \%$ of the second group. A similar 5-year relapse rate $(80 \%)$ was obtained in a group of thirty patients from another area with a more varied rice diet. The author attributes this difference to the increased mastication required by the unrefined wheat diet, which is associated with an increase in saliva, lower stomach acidity and reduced bile output.
\end{abstract}

\section{Introduction}

Duodenal ulcer is known to be more common in the rice-eating areas of India and Pakistan than in the wheat-eating areas (Malhotra, 1967a). This difference in incidence has been attributed to the differences in diet and eating habits, but so far no controlled trials have been done to substantiate this. In the present trial one half of a group of forty-two patients with chronic duodenal ulcer at a Railway Hospital in Bombay were persuaded to change to an unrefined wheat diet and to masticate it well. They were followed up for a 5-year period. The incidence of relapses in this period was compared with a similar group who continued with their customary rice diet.

As a check, the relapse rate in another group of thirty duodenal ulcer patients on a more varied rice diet at the Railway Hospital in Ratlam was determined over the same 5-year period.

\section{Method}

The patients were all male between 25 and 55 years with chronic but active ulcers confirmed by radiological evidence of deformity of the duodenal cap or an ulcer crater. They were admitted for a period of 4 to 6 weeks. The patients at the Bombay hospital were divided into two groups of twenty-one

Address for reprints: Dr S. L. Malhotra, 11 Garden Reach Road, Calcutta-43, India. using randomized numbers. The groups were similar in age, duration of illness and dietary classification. The mean age for the first group was 32 years and $\triangle$ for the second group 35 years. Their normal staple diet was made up of rice and lentil curries.

The group of thirty patients in the Ratlam hospital ${ }^{\circ}$

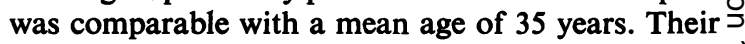
staple diet was rice with lentil or fish or meat curry $\vec{c}$ and ragi or maize gruel.

The first group of the Bombay patients were changed to an unrefined wheat diet of thick chapattis cooked with ghee (clarified butter), thick dhal and $\overrightarrow{0}$ vegetable curries and yoghurt or yoghurt sherb8t taken sip by sip. The patients were told to che each mouthful deliberately more than 60 times that the saliva admixed with it and the food bolus became a slimy, thin, sweet end-product before being swallowed. In addition they were allowed smallo doses of aluminium hydroxide gel (AHG) if and $\varrho$ when they had severe pain.

The other groups of patients were given initially milk $120 \mathrm{ml}$ 4-hourly and later in addition 4-hourly rice with thin lentil soup and meat or fish curries. Four patients at the Bombay hospital and three at음 Ratlam required milk drips. They were also given. 4-hourly AHG supplemented by anticholinergic $\frac{3}{3}$ drugs (Antrenyl Duplex, Ciba) and phenobarbital.

All the patients were kept in until there was $\frac{O}{3}$ clinical and radiological evidence of healing of their ulcers. Fibre endoscopy was not available.

The first group were discharged with instructions $\frac{D}{0}$ to continue on the unrefined wheat diet and to masticate it as when in hospital. They were given N no medicines. The others continued on their customary diet. No antacids or anticholinergics were prescribed as a routine but were given if any dyspepsia $\omega$ recurred (with milk 4-hourly, also in the Ratlam? centre). All were asked to reduce smoking.

The patients were followed-up bi-weekly for $6 \Phi$ months and then at 6-monthly intervals for 5 years. At each follow-up a detailed questionnaire was com- -0 pleted. Further barium meals were given as indi- $-\frac{\vec{T}}{\mathrm{~d}}$ cated. The patients on the 'masticatory' wheat diet? 
adhered to the diet because they themselves realized the improvement in their symptoms.

Clinical assessment was made independently by two physicians in each hospital who were not connected with the trial and, in the Bombay hospital, who did not know which dietary group the patient was in. Another doctor checked that they were continuing their diet. The X-rays were also examined independently by a radiologist not connected with the trial and not knowing the group to which the patients belonged. In the Bombay series there was no difference between the two groups in weight or nutritional status at the beginning and end of the 5-year period.

\section{Results}

During their stay in hospital all patients became symptom-free within 2-4 weeks and were discharged when there was radiological evidence of healing at 4-6 weeks. The results of the follow-up are shown in Table 1.

At the end of 1 year in the Bombay group on the masticatory wheat diet and no medicine, two $(9 \%)$

TABLE 1. The clinical and radiological relapse rates in seventy-two patients with peptic ulcer treated with three different dietary regimes

\begin{tabular}{lcccc}
\hline & \multicolumn{4}{c}{ No. $(\%)$ of patients with relapse } \\
\cline { 2 - 5 } $\begin{array}{l}\text { Time } \\
\text { interval }\end{array}$ & Group A* & Group B $\dagger$ & Group C $\ddagger$ \\
\hline 12 months & 2 & $(9)$ & $9(43.0)$ & $14(46)$ \\
24 months & 0 & & $6(28 \cdot 5)$ & $5(17)$ \\
5 years & 1 & $(5)$ & $2(9 \cdot 5)$ & $5(17)$ \\
Total & $3(14)$ & $17(81)$ & $24(80)$ \\
\hline
\end{tabular}

* Group A: Bombay group (twenty-one patients) with duodenal ulcer on a fibre/rich masticatory diet.

$\dagger$ Group B; Bombay group (twenty-one patients) with duodenal ulcer on a fibre-poor non-masticatory diet.

$\ddagger$ Group C; Ratlam group (thirty patients) with duodenal ulcer on a fibre-poor non-masticatory diet.

\section{Statistical analysis}

1. Gp A v Gps B and C: $\chi^{2}=27.4$; significant at $P<0.001$.

2. Gp A v Gp B v Gp C: $\chi^{2}=27.38$; significant at $P<0.001$.

3. ' $F$ '-test for equality of variance for Gps A, B and C. $F=21 \cdot 30$ (Table $F=4.92$ at $1 \%$ significance level).

There is a significant difference between A, B and C. The probability of this happening by chance is $<1 \%$. By inspection $\mathbf{G p ~} A$ is the one which differs significantly.

4. Student's ' $t$ '-test to establish whether Gps $B$ and $C$ are comparable and not related by chance. $t=0.087 ;>90 \%$ of confidence level.

5. Prognosis: a best curve fit employing a least square exponential technique was employed to project the results $A, B$ and $C$ to 10 years. The anticipated further relapses at 10 years were: Group A, one relapse; Group B, two; Group C, three relapses. had relapsed. In the other Bombay group, nine $(43 \%)$, and in the Ratlam group, fourteen $(46 \%)$ had had clinical and radiological recurrences. The corresponding figures at 2 years were still $9 \%$ in the first group and had risen to $71.5 \%$ and $63 \%$ respectively in the other two groups. At the end of 5 years one more patient had relapsed in the first group $(14 \%)$ and the relapse rate in the other two groups had risen to $81 \%$ and $80 \%$. In the Ratlam group two patients had had melaena, two had developed pyloric stenosis and one had perforated. Using the $\chi^{2}$ test, the differences in the relapse rates are statistically signficant $(P<0 \cdot 001)$.

\section{Discussion}

The high relapse rate in the groups continuing on a rice diet are in general agreement with those found by Flood (1956) of 78\%, Romke and Loken (1956) of $86 \%$ and Silon (1975).

The incidence of duodenal ulcer is high in the rice-eating areas of India, Pakistan and Bangladesh, and low in those areas of the Punjab and Rajasthan where the staple diet is unrefined wheat in the form of chapattis (Dogra, 1940; Hadley, 1959; Malhotra, $1964,1967 \mathrm{c})$. This distribution fits in with the hypothesis of Cleave (1962) which relates the incidence of peptic ulcer to the consumption of refined carbohydrate food and especially sugar. He attaches importance to the buffering effect of unrefined foods. This has been questioned by Tovey (1974).

The diet in the wheat-eating areas also contains more of the protective factors propounded by Cheney (Jayaraj, Tovey and Clark, 1976). The author (Malhotra, 1967a, 1970) also has produced evidence supporting the hypothesis that the amount of mastication required is important. The chapattis of the unrefined wheat diet naturally require much more mastication than the sloppier diet of the riceeating areas.

Several controlled studies have cast doubt on the efficacy of traditional 'gastric' diets in the treatment of peptic ulcer (Lawrence, 1952; Doll, Friedlander and Pygatt, 1956; Spira, 1956; Evans, 1957; Truelove, 1960; Doll, 1964; Gillespie, 1967). LennardJones and Babouris (1965) showed that gastric acidity in twelve duodenal ulcer patients was no greater when they ate a completely 'free choice' diet than when they ate a typical 'therapeutic' diet as conventionally advised for peptic ulcer.

In all these studies the emphasis was on the pattern of diet and not on the pattern of eating. In the author's view both are important. It is not only what we eat but even more how we eat it that is relevant in peptic ulcer disease. The chewing movements of the jaw, and the patterns of diet and eating, increase not only the quantity of saliva secreted, but also bring about a rise in its mucus content and buffer 
capacity (Dewar, 1952; Dewar and Parfitt, 1954; Malhotra, 1967b, 1968c). These result in a lowering of gastric acidity (Hadley, 1959; Malhotra, 1967a, 1970).

In addition to the cereal fibre of unrefined carbohydrates, the amount of vegetable fibre in the diet is important. The mode of action of fibre is partly that it requires thorough chewing, producing mucusrich saliva. It also ferments in the bowel lumen, liberating large quantities of acetic acid (Popjack, French and Folley, 1951). Shortchain fatty acids produce no contraction of the gall bladder, whereas long-chain fatty acids produce a powerful contraction (Sarles, 1965). Milk and fermented milk products such as ghee butter and cheese (made by fermentation processes and not by creamery processes), yoghurt and especially yoghurt sherbet (made by vigorous churning of yoghurt with sugar and ice) are rich in short-chain fatty acids of the $\mathrm{C}_{4}, \mathrm{C}_{6}$ series. In all communities in which peptic ulcer is common long-chain $\left(\mathrm{C}_{18: 1}\right)$ fatty acid triglycerides are predominant in the diet.

It has also been shown that a 'masticatory' diet is accompanied by lower urobilinogen output in the faeces. The reduced acidity in the stomach due to the increased amount of saliva and mucus on a high masticatory diet is accompanied by a reduced flow rate of bile and reduced gall-bladder contraction (Malhotra, 1967d, 1968a,b,d). Higher flow rates of bile result in a more alkaline bile (Hong, Magee and Crewdson, 1956), whereas a longer storage in the gall bladder with the absorption of water and bicarbonate ions results in a more neutral bile (Magee, 1965). The mucus of the mucous cells is rendered fluid and is lost from the cells in an alkaline environment. This can result in inflammatory changes (Ball and James, 1961; Lawson, 1964; Malhotra, 1967b). Bile itself also damages the mucosa and leads to increased 'back diffusion' (Davenport, 1970) and gastritic changes (du Plessis, 1965).

Lawson (1964) showed experimentally that bile in the stomach produces chronic atrophic gastritis which is a precursor of gastric ulcer (Rivers and Gardner, 1940; Spira, 1956; Malhotra, 1967b, 1970). du Plessis (1965) found a high concentration of bile acid conjugates in the gastric juice of gastric ulcer patients and Capper (1969) found that they had a marked pyloric reflux of bile.

It is possible that increased reflux of bile into the duodenal cap may be a cause of duodenal ulcer also. In patients with both gastric and duodenal ulcers, it is always the duodenal ulcer which precedes the gastric ulcer. If acid alone were the cause without the involvement of bile the sequence would be different.

\section{Conclusions}

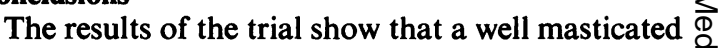
unrefined wheat diet supplemented by milk and fer- $c$ mented milk products is successful in preventing $\vec{\Rightarrow}$ relapses in patients with healed duodenal ulcers. $\stackrel{9}{+}$ The importance not only of a high-fibre unrefined diet but also of adequate chewing resulting in an 을 increase in saliva and in its buffer capacity and $\frac{\infty}{\vec{D}}$ reduced bile flow is stressed (Malhotra, 1966).

\section{Acknowledgments}

I am deeply grateful to Dr V. D. Mathur, M.S., Surgeon $\vec{\circ}$ and District Medical Officer, Jagjiwan Ram Hospital, Bom- bay, for the random allocation of the Bombay patients in the $\vec{\omega}$ two sub-groups, and to Dr H. D. Astik, District Medical Officer, Ratlam, for his invaluable help. I would also like to thank Dr E. Billimoria, Honorary Consultant in Radiology, J.J. Group of Hospitals, Bombay, for his invaluable and painstaking help in reviewing the $X$-rays. I must also thank $A$ the resident medical staff of the Jagjiwan Ram Hospital and $\delta$ the Railway Hospital, Ratlam, for assessing the results in the three groups of patients; and Mr P. R. N. Gibbons, M.A., क B.Sc., C.Eng., M.R.A.S., for the statistical analysis.

My thanks are also due to Sir Francis Avery Jones, K.B.E., M.D., F.R.C.P. and especially $\mathrm{Mr}$ F. I. Tovey, O.B.E. Ch.M., F.R.C.S., for invaluable help in reading the manuscript and making helpful suggestions.

\section{References}

Ball, P.A.J. \& JAmes, A.H. (1961) The historical background $\overrightarrow{0}$ to gastric ulcer. Lancet, i, 1365.

CAPPER, W.M. (1969) Significance of the pyloric valve $\infty$ gastro-oesophageal pathology. Proceedings of the Roy Society of Medicine, 62, 1247.

Cleave, T.L. (1962) Peptic Ulceration. John Wright \& Sons, Bristol.

DAVENPORT, H.W. (1970) Back diffusion of acid through the gastric mucosa and its physiological consequences. In: $\mathbb{D}$ Progress in Gastroenterology, Vol. 2 (Ed by G. B. J. Glass). Grune and Stratton, New York and London.

DewAR, M.R. (1952) An investigation of the physical, 3 clinical and bacterial properties of saliva, with special reference to mucus contents and their correlation with susceptibility to dental caries. Ph.D. Thesis. University of London.

Dewar, M.R. \& Parfitt, G.J. (1954) An investigation of the physical properties of saliva and their relationship to the $\bar{\sigma}$ mucin content. Journal of Dental Research, 33, 751.

DU Plessis, D.J. (1965) Pathogenesis of gastric ulceration. Lancet, i, 974.

DogRA, J.R. (1940) Studies on peptic ulcer in South India. Indian Journal of Medical Research, 28, 145.

Doll, R. (1964) Medical treatment of gastric ulcer. Scandinavian Medical Journal, 9, 183.

Doll, R., Friedlander, P. \& Pygatt, F. (1956) Dietetic treatment of peptic ulcer. Lancet, i, 5 .

EvaNS, P.R.C. (1957) Value of strict dieting, drugs and $\mathcal{S}$ 'Robaden' in peptic ulceration. British Medical Journal, N 1,612 .

FLOOD, O.A. (1956) The results of medical treatment of $\mathrm{\omega}$ peptic ulcer. Journal of Chronic Disease, 1, 43.

GillesPIE, I.E. (1967) Duodenal ulcer. British Medical Journal, 4, 281, 339.

HADLEY, C.G. (1959) Studies of peptic ulcer found in $\mathbb{D}$ South India. Indian Council of Medical Research, No. 39, p. 31 .

Hong, S.S., Magee, D.F. \& Crewdson, F. (1956) The physiological regulation of gall-bladder evacuation. Gastroenterology, 30, 625. 
JayaraJ, A.P., Tovey, F.I. \& Clark, C.G. (1976) The possibility of dietary protective factors in duodenal ulcer. II. Postgraduate Medical Journal, 52, 640.

LAWRENCE, J.S. (1952) Dietetic and other methods in the treatment of peptic ulcer. Lancet, i, 696.

LAwSON, H.H. (1964) Effect of duodenal contents on the gastric mucosa under experimental conditions. Lancet, i, 469.

LENNARD-Jones, J.E \& Babouris, N. (1965) Effect of different foods on the acidity of the gastric contents in patients with duodenal ulcer. Gut, 6, 113 .

MAGEe, D.F. (1965) The physiology of the gall bladder emptying. In: The Biliary System. A Symposium of the NATO Advanced Study Institute (Ed. by W. Taylor), p. 235. Blackwell Scientific Publications, Oxford.

Malmotra, S.L. (1964) Peptic ulcer in India and its aetiology. Gut, 5, 412 .

Malmotra, S.L. (1966) Diets for peptic ulcer. British Medical Journal, 1, 292.

Malhotra, S.L. (1967a) Protective action of saliva in peptic ulcer. Study of its effects on gastric acidity by dyedilution technique. Scandinavian Journal of Gastroentero$\log y, 2,95$.

Malmotra, S.L. (1967b) A study of the effect of saliva on the concentration of mucin in gastric juice and its possible action on saliva. American Journal of Digestive Disease, $15,489$.

Malhotra, S.L. (1967c) Epidemiology of peptic ulcer in South India and the ulcer change. Gut, 8, 180.

Malhotra, S.L. (1967d) Faecal urobilinogen content in populations with different peptic ulcer incidence in India and its possible role in the aetiology of ulceration. Scandinavian Journal of Gastroenterology, 2, 337.

Malhotra, S.L. (1968a) Effect of diet on faecal and urine urobilinogen excretion and its possible relationship to the pathogenesis of peptic ulceration. Gut, 9, 183.
Malhotra, S.L. (1968b) Effect of pattern of eating and antacids on faecal urobilinogen. Gut, 9, 38.

Malhotra, S.L. (1968c) Role of saliva in the aetiology of peptic ulcer. British Medical Journal, 1, 1220.

Malhotra, S.L. (1968d) Epidemiological study of cholelithiasis among railroad workers in India with special reference to causation. Gut, 9, 290.

Malhotra, S.L. (1970) New approaches to the problem of the pathogenesis of peptic ulcer based on the protective action of saliva. American Journal of Digestive Disease, 15, 489.

Popjack, G., French, T.H. \& Folley, S.J. (1951) Utilization of acetate for milk-fat synthesis in the lactating goat. Biochemical Journal, 48, 411.

Rivers, A.B. \& Gardener, J.W. (1940) Recurrent peptic ulcer. Journal of the American Medical Association, 115, 1779.

Romke, O. \& Loken, E. (1956) Prognosis of peptic ulcer in young patients. Acta medica scandinavica, 155, 373.

Sarles, H. (1965) Quoted in The Biliary System. A Symposium of the NATO Advanced Study Institute (Ed. by W. Taylor), Blackwell Scientific Publications, Oxford.

Silon, W. (1975) Peptic ulcer. In: Harrison's Principles of Internal Medicine, 7th edn, p. 1438 .New York, St Louis, etc., McGraw-Hill.

SPIRA, J.J. (1956) Gastro-Duodenal Ulcer. London, Butterworths.

Tovey, F.I. (1974) Aetiology of duodenal ulcer: an investigation into the buffering action and effect on pepsin of bran and unrefined carbohydrate foods. Postgraduate Medical Journal, 50, 683.

Truelove, S.C. (1960) Stilboestrol, phenobarbitone and diet in chronic duodenal ulcer. British Medical Journal, 2, 559. 